\title{
Influence of Al on the Structure and in Vitro Behavior of Hydroxyapatite Nanopowders
}

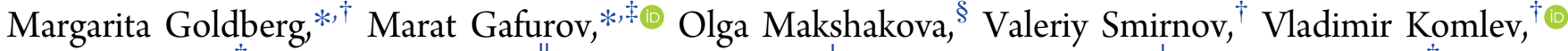 \\ Sergei Barinov, ${ }^{\dagger}$ Egor Kudryavtsev, ${ }^{\|}$Natalia Sergeeva, ${ }^{\perp}$ Suraya Achmedova, ${ }^{\perp}$ Georgy Mamin, ${ }^{\ddagger}$ \\ Fadis Murzakhanov, and Sergei Orlinskii ${ }^{\ddagger}$
}

\begin{abstract}
${ }^{\dagger}$ A.A. Baikov Institute of Metallurgy and Materials Science, Russian Academy of Sciences, 49 Leninsky pr., 119334 Moscow, Russia
${ }^{\ddagger}$ Kazan Federal University, 18 Kremlevskaya Street, 420008 Kazan, Russia

${ }^{\S}$ Kazan Institute of Biochemistry and Biophysics, FRC Kazan Scientific Center of RAS, Lobachevsky Str. 2/31, 420111 Kazan, Russian Federation

"The National Research University "Belgorod State University", 85 Pobedy str., 308015 Belgorod, Russia

${ }^{\perp}$ Federal State Budgetary Institution, National Medical Research Radiological Center of the Ministry of Health of the Russian Federation, 3 2nd Botkinsky pass., 125284 Moscow, Russia
\end{abstract}

ABSTRACT: Nanopowders of aluminum-substituted (0-20 mol \%) hydroxyapatite (HA) with the average size of 40-60 nm were synthesized by the precipitation method from nitrate solutions. A series of samples were studied by various analytical tools to elucidate the peculiarities of $\mathrm{Al}$ introduction. Electron paramagnetic resonance and pulsed electron-nuclear double resonance data demonstrate that incorporation of $\mathrm{Al}$ resulted in a decrease in the concentration of impurity carbonate anions and lead to an increase in the number of protons in the distant environment of the impurity nitrogen species. Density functional theory calculations show that the $\mathrm{Al}^{3+}$ incorporation is accompanied by the local positional rearrangement and the distortion of anion channel geometry. An in vitro test conducted on MG-63 cells demonstrates the cytocompatibility and magnification of the surface matrix characteristics with Al doping.

\section{INTRODUCTION}

Hydroxyapatite (HA) is one of the most attractive biomaterials for bone reconstruction due to its excellent biological compatibility and osteoconductivity. ${ }^{1,2}$ During recent years, much efforts have been done in developing synthetic HA to enhance its biological and mechanical properties for use in biomedical applications that can be mainly achieved by cationic substitutions of calcium ions. ${ }^{3}$ Aluminum can serve as one of the substituents for increasing the densification during the sintering of bioceramic materials. ${ }^{4}$ Composite materials based on hydroxyapatite and $\mathrm{Al}_{2} \mathrm{O}_{3}$ with the formation of $\mathrm{Al}-\mathrm{HA}$ containing clinoptilolite demonstrated biocompatibility and absence of acute toxicity for SAOS- 2 cells. ${ }^{5}$ Kolekar et al. synthesized aluminum-doped HA powders by the solution combustion method with heat treatment at $950{ }^{\circ} \mathrm{C}$ and showed the absence of toxic effects for Al-HA particles on cell lines L929. ${ }^{6}$ At the same time, some studies also suggest that $\mathrm{Al}$ (in drinking water, for instance) is linked with brain dementia, including Alzheimer's disease. ${ }^{7,8}$ However, other investigations demonstrate the absence of the difference between the $\mathrm{Al}$ content in the human brains of healthy people and Alzheimer's disease patients. 9 Thus, the biological effect of $\mathrm{Al}$ remains controversial (both positive and negative functions of the element in the human body have been reported). ${ }^{10}$

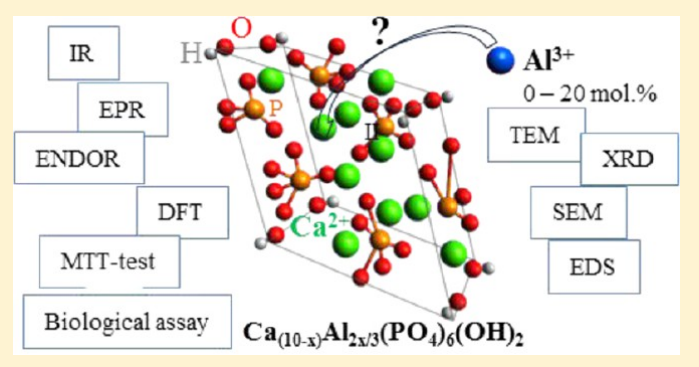

Besides being used in developing bioceramics, Al-HA is a promising material for other applications. Al-HA is considered as an efficient membrane adsorbent for fluoride in groundwater purification. ${ }^{11,12}$ The nanoscale powders of Al-HA are proposed for drug delivery. ${ }^{6}$ The composite materials based on Al-HA and $\mathrm{AlPO}_{4}$ with $(\mathrm{Ca}+\mathrm{Al}) / \mathrm{P}=1.62$ and $\mathrm{Ca} / \mathrm{Al}=1.02$ are considered as the catalysts for dehydration of ethanol to diethyl ether. ${ }^{13}$

Hydroxyapatite can be found in nature in two different phases: hexagonal and monoclinic, the latter probably associated with the stoichiometric HA. ${ }^{14,15}$ In the present work, we investigate the hexagonal form of $\mathrm{HA}$ with a space group of $\mathrm{Pb}_{3} /$ $m$. This type of HA is involved in bone formation. The crystal structure of HA has been described in details by Kay et al. ${ }^{16}$ There are four different types of crystallographic positions in the apatitic unit cell. Four calcium ions per unit cell, called $\mathrm{Ca}(\mathrm{I})$, are in columns parallel to the $c$ axis and are surrounded by nine oxygen atoms. Other calcium ions, six per unit cell, called $\mathrm{Ca}$ (II), form two equilateral triangles along the $c$ axis at $z=1 / 4$ and 3/4, a so-called anion channel. Hydroxyl groups are located on the hexagonal $c$ axis. The structure is completed by six $\mathrm{PO}_{4}{ }^{3-}$ anions, where each $\mathrm{P}$ atom is coordinated by four oxygen atoms.

Received: August 27, 2019

Revised: October 3, 2019

Published: October 8, 2019 
Table 1. Powders' Composition, Lattice Parameters, and Crystalline Sizes

\begin{tabular}{|c|c|c|c|c|c|c|c|c|c|c|}
\hline $\begin{array}{c}\text { Ca } \\
\text { substitution } \\
\text { by Al,mol \% }\end{array}$ & stoichiometric formulae & $\begin{array}{c}m \\
\mathrm{Ca}\left(\mathrm{NO}_{3}\right)_{2} \\
4 \mathrm{H}_{2} \mathrm{O}, \mathrm{g}\end{array}$ & $\begin{array}{c}m \\
\mathrm{Al}\left(\mathrm{NO}_{3}\right)_{3} . \\
9 \mathrm{H}_{2} \mathrm{O}, \mathrm{g}\end{array}$ & $\begin{array}{c}m \\
\left(\mathrm{NH}_{4}\right)_{2} \\
\mathrm{HPO}_{4}, \mathrm{~g}\end{array}$ & $\begin{array}{l}\mathrm{Al} \\
\text { theoretical, } \\
\text { mol \% }\end{array}$ & $\begin{array}{l}\mathrm{Al} \\
\text { theoretical, } \\
\text { wt } \%\end{array}$ & $\begin{array}{c}\mathrm{Al} \\
\text { measured, } \\
\text { wt } \%\end{array}$ & $\begin{array}{c}\text { cell } \\
\text { parameter } \\
a, \mathrm{~nm}\end{array}$ & $\underset{\mathrm{nm}}{\text { parameter } c \text {, }}$ & $D, \mathrm{~nm}$ \\
\hline 0 & $\mathrm{Ca}_{10}\left(\mathrm{PO}_{4}\right)_{6}(\mathrm{OH})_{2}$ & 58.76 & 0.00 & 19.72 & 0 & 0 & $<10^{-4}$ & $0.9441(7)$ & $0.6890(8)$ & $20(3)$ \\
\hline 0.5 & $\mathrm{Ca}_{9.95} \mathrm{Al}_{0.033}\left(\mathrm{PO}_{4}\right)_{6}(\mathrm{OH})_{2}$ & 58.54 & 0.31 & 19.74 & 0.5 & 0.086 & $0.082(3)$ & $0.9442(7)$ & $0.6888(6)$ & $23(4)$ \\
\hline 5 & $\mathrm{Ca}_{9.5} \mathrm{Al}_{0.33}\left(\mathrm{PO}_{4}\right)_{6}(\mathrm{OH})_{2}$ & 56.46 & 3.14 & 19.95 & 5 & 0.876 & $0.84(3)$ & $0.9425(7)$ & $0.6885(6)$ & $19(4)$ \\
\hline 20 & $\mathrm{Ca}_{8} \mathrm{Al}_{1.33}\left(\mathrm{PO}_{4}\right)_{6}(\mathrm{OH})_{2}$ & 49.23 & 13.01 & 20.65 & 20 & 3.629 & $3.62(4)$ & $0.9421(8)$ & $0.6859(8)$ & $18(5)$ \\
\hline
\end{tabular}

Generally, the localization of the substituting cation in the apatite structure correlates to its ionic radius. ${ }^{17} \mathrm{Al}^{3+}$ can substitute both $\mathrm{Ca}(\mathrm{I})$ and $\mathrm{Ca}(\mathrm{II})$ sites, causing significant lattice distortions: the $\mathrm{Ca}(\mathrm{I})$ site is smaller in volume than the $\mathrm{Ca}$ (II) site, while the ionic radius of $\mathrm{Al}^{3+}$ is less than this for $\mathrm{Ca}^{2+}(0.051$ and $0.104 \mathrm{~nm}$, respectively). ${ }^{17}$ In ref 18 , Nounah et al. discussed the impact of site volume. It was assumed that the introduced ions prefer to occupy a calcium site with the corresponding volume that leads to speculation of the preferred $\mathrm{Ca}(\mathrm{I})$ position for $\mathrm{Al}^{3+}$. However, the charge of the ions and the strength of the corresponding bonds also influence the distribution of the substitutional cations between $\mathrm{Ca}(\mathrm{I})$ and $\mathrm{Ca}(\mathrm{II})$. As the trivalent cation $\mathrm{Al}$ substitutes divalent $\mathrm{Ca}$, a charge compensation is needed. According to the density functional theory (DFT) calculations, $\mathrm{Al}^{3+}$ preferentially substitutes the $\mathrm{Ca}(\mathrm{II})$ site with the formation of $\mathrm{Ca}^{2+}$ vacancy. ${ }^{10}$ However, the authors of ref 10 did not take into account in their calculations other charge compensation mechanisms like the loss of the $\mathrm{H}$ atom in the $\mathrm{OH}$ group. The charge compensation scheme might also depend on the way of HA synthesis.

There are different methods of Al-HA nanoparticles synthesis besides the solution combustion method. ${ }^{6}$ Wakamura et al. obtained pure $\mathrm{Al}-\mathrm{HA}$ nanoparticles by coprecipitation and ionexchange methods. ${ }^{19}$ Fahami et al. applied the mechanical activation method and acquired Al-HA nanoparticles with the nanospheroids with an average size of $44 \pm 20 \mathrm{~nm} .{ }^{20}$ Nie et al. synthesized aluminum-substituted hydroxyapatite powders with $\mathrm{Al} / \mathrm{Ca}$ from 0 to 0.5 . by the coprecipitation method and obtained nanoparticles without any impurity phases in assynthesized materials. ${ }^{12}$

In our previous work, we demonstrated enhanced solubility of $\mathrm{Al}$ in the $\beta$-tricalcium phosphate matrix synthesized by the precipitation method. ${ }^{13}$ In the present paper, we use the same reaction route to synthesize aluminum-substituted hydroxyapatite powders and to investigate them by different analytical methods to follow the changes caused by aluminum introduction. Among the analytical tools usually used for HA sample characterization, we have comprehensively studied the Al-HA species by electron paramagnetic resonance (EPR) spectroscopy in both conventional (cw) and pulsed (electron spin-echo, ESE) modes and pulsed electron-nuclear double resonance (ENDOR) spectroscopy in two frequency ranges: $\mathrm{X}$ band (microwave frequency of $\left.\nu_{\mathrm{mw}} \approx 9 \mathrm{GHz}\right)$ and $\mathrm{W}$-band $\left(\nu_{\mathrm{mw}}\right.$ $\approx 95 \mathrm{GHz}$ ). The obtained experimental results are compared with the performed DFT calculations.

\section{MATERIALS AND METHODS}

2.1. Synthesis. Samples of Al-HA with the chemical formula $\mathrm{Ca}_{10-x} \mathrm{Al}_{2 x / 3}\left(\mathrm{PO}_{4}\right)_{6}(\mathrm{OH})_{2}$ were synthesized with $X=0 ; 0.005$; $0.05 ; 0.2$. The ratio of $\mathrm{Ca} / \mathrm{Al}$ as $(10-x) /(2 x / 3)$ was selected for taking into account the valency of $\mathrm{Ca}^{2+}$ and $\mathrm{Al}^{3+}$ to save the charge balance of the compound. The synthesis was conducted by the precipitation method according to the following reaction using reactants of analytical grade and double-deionized water:

$$
\begin{gathered}
(10-x) \mathrm{Ca}\left(\mathrm{NO}_{3}\right)_{2}+6\left(\mathrm{NH}_{4}\right)_{2} \mathrm{HPO}_{4}+(2 x / 3) \mathrm{Al}\left(\mathrm{NO}_{3}\right)_{3} \\
+8 \mathrm{NH}_{4} \mathrm{OH} \rightarrow \mathrm{Ca}_{(10-x)} \mathrm{Al}_{2 x / 3}\left(\mathrm{PO}_{4}\right)_{6}(\mathrm{OH})_{2}+20 \\
\mathrm{NH}_{4} \mathrm{NO}_{3}+6 \mathrm{H}_{2} \mathrm{O}
\end{gathered}
$$

The amount of initial reagents is listed in Table 1 . The diammonium hydrogen phosphate solution was added dropwise into calcium and aluminum nitrate solutions during permanent mixing by the overhead stirrer. The $\mathrm{pH}$ of the reaction mixture was maintained at a level of $9.0-9.5$ by adding aqueous ammonia. Powders were ripened at the mother solution for 21 days at a temperature of $25{ }^{\circ} \mathrm{C}$ for full crystallization of the precipitate. $^{21,22}$ Obtained powders were separated by vacuumsuction filtration, washed in deionized water three times, and dried at $60^{\circ} \mathrm{C}$ for $24 \mathrm{~h}$. The powders were heat-treated at $300^{\circ} \mathrm{C}$ for $3 \mathrm{~h}$ in air to remove ammonium nitrate, an impurity phase.

2.2. Powder Characterizations. For determination of $\mathrm{Al}$ content in the precipitates, powders were heat-treated at $900{ }^{\circ} \mathrm{C}$ for water removal, dissolved in a $\mathrm{HCl}-\mathrm{HNO}_{3}$ mixture, and analyzed by atomic emission spectroscopy with inductively coupled plasma (AES-ICP, HORIBA Jobin Yvon, ULTIMA 2). The powder materials were characterized by the $\mathrm{X}$-ray diffraction (XRD) method (Shimadzu XRD-6000, Cu K $\alpha$ radiation, $2 \theta$ range from 10 to $60^{\circ}$ with a step of $0.02^{\circ}$ ) with the identification of phase composition according to JCPDS and PCPDFWIN databases. The lattice parameters of $\mathrm{HA}$ were determined by the Rietveld refinement method. The Gaussian fit obtained by Origin software was used for establishing the peak (002) full width at half-maxima for calculating the crystalline size (D) by the Scherrer equation ${ }^{23}$ according to

$$
D=k \lambda /\left(B_{1 / 2} \cos \theta\right)
$$

where $k$ is the shape factor equal to $0.9, \lambda=0.15406 \mathrm{~nm}$ is the wavelength of X-rays, $B_{1 / 2}$ is the full width at half-maximum (FWHM) of X-ray reflection in radians, and $\theta$ is the Bragg diffraction angle. Fourier-transformed infrared absorption (FTIR) spectra of the samples were measured using $\mathrm{KBr}$ on a Nikolet Avatar FTIR spectrometer, and spectra were obtained in the range from 4000 to $400 \mathrm{~cm}^{-1}$ to evaluate the functional group of the specimens. The particle morphology of synthesized powders was assessed by field emission gun scanning electron microscopy (FEG SEM) (CrossBeam 1540 EsB, Carl Zeiss, gold sputtered specimens in the SEM mode, accelerating voltage of 7 $\mathrm{kV}, 5 \mathrm{~mm} \mathrm{WD}, 30 \mu \mathrm{m}$ aperture size). The particle investigations were also conducted by transmission electron microscopy (TEM) with X-ray energy-dispersive spectroscopy (XEDS) in the mapping mode to establish the elements' distribution in powders (JEOL JEM 2100 with Oxford Inca, carbon sputtered specimens, accelerating voltage of $200 \mathrm{kV}$ ).

Conventional and pulsed X-band and W-band EPR measurements were carried out on a Bruker ElexSys 580/680 
spectrometer (Bruker). Field swept electron spin echo (FS ESE) spectra were recorded with the standard pulse sequence $\pi / 2-\tau$ $-\pi$ with a $\pi / 2$ pulse duration of $40 \mathrm{~ns}$ for the $\mathrm{W}$-band and $16 \mathrm{~ns}$ for the X-band and a minimal time delay $\tau=240 \mathrm{~ns}$. $T_{2 \mathrm{e}}$ was studied by tracking the primary ESE amplitude with the same $\pi$ / $2-\pi$ pulse durations while varying $\tau$ with the minimal possible step of $4 \mathrm{~ns}$. $T_{1 \mathrm{e}}$ was extracted from an inversion-recovery experiment by applying the $\pi-T_{\text {delay }}-\pi / 2-\tau-\pi$ pulse sequence, where both the $\pi$ pulse duration and $\tau$ are fixed while $T_{\text {delay }}$ is varied. For Mims ENDOR, ${ }^{24}$ the pulse sequence $\pi / 2-\tau$ $-\pi / 2-T-\pi / 2$ with an additional RF pulse $\pi_{\mathrm{RF}}=18 \mu \mathrm{s}$ (optimized for ${ }^{1} \mathrm{H}$ nuclei) inserted between the second and third microwave $\pi / 2$ pulses was applied. The RF frequency in this setup could be swept in the range of $1-200 \mathrm{MHz}$. EPR spectra were simulated with the EasySpin utility. ${ }^{25}$ To create stable paramagnetic centers in the nominal pure material, X-ray irradiation of the synthesized powders was provided by using a URS-55 source $(U=55 \mathrm{kV}, I=16 \mathrm{~mA}, \mathrm{~W}$ anticathode $)$ at room temperature during $30 \mathrm{~min}$. with the estimated dose of $5 \mathrm{kGy} .^{26}$

The calculations were carried out on the basis of the density functional theory with the plane-wave basis and Vanderbilt ultrasoft pseudopotentials ${ }^{27}$ employing the Quantum ESPRESSO program package. ${ }^{28}$ The generalized-gradient approximation for the exchange-correlation functional of Perdew, Burke, and Ernzerhof (GGA-PBE) ${ }^{29}$ was used. Kinetic energy cutoffs of 45 Ry for the smooth part of the electron wave functions and 300 Ry for the augmented electron density were set up.

The initial geometry and the unit-cell parameters for HA were taken from. ${ }^{30}$ The $1 \times 1 \times 1$ monoclinic supercell (space group $P 21 / b$ with 88 atoms in the cell) previously was proved to be sufficient to reproduce EPR and ENDOR spectra ${ }^{31}$ and phonon spectra $^{32}$ of both pure and doped HA crystals and, thus, was used for the present study. The difference in the notations of principal axes for the monoclinic (used in the calculations) and hexagonal (used in the experiment) modifications, as it is demonstrated by our results, should not lead to confusion.

The geometry optimization was performed in two steps. In the first step, the atomic positions were allowed to relax keeping the cell parameter fixed and then both the coordinates and cell dimensions were fully relaxed. The convergence condition on forces was $10^{-3}$ au. The Brillouin zone integration was performed on a Monkhorst-Pack $2 \times 2 \times 1$ k-point mesh. ${ }^{33}$

In vitro cytotoxicity of bioceramics granules based on $\mathrm{HA}$, $0.5 \mathrm{Al}-\mathrm{HA}$, and 20Al-HA was carried out by using the MTT assay using a model cell line of human osteosarcoma MG-63 (Russian Collection of Cell Cultures, Institute of Cytology, Russian Academy of Sciences, St. Petersburg). Bioceramic granules were obtained according to the technology described by Komlev et al. ${ }^{34}$ In short, the slurry of polymer and powder was introduced into hot oil media during the rotation of the stirrer. Granules were formed due to the effect of immiscible liquids. Further sintering was conducted at $1200^{\circ} \mathrm{C}$ during $2 \mathrm{~h}$. The morphology of bioceramic granules was characterized by SEM. The sterile samples (dry heat sterilization at $180{ }^{\circ} \mathrm{C}$ during $1.5 \mathrm{~h}$ ) of bioceramic granules were placed into 96-well plates for cultivation (Corning Costar) into triplets with one plate per incubation period and covered with complete growth medium (CGM) that contained DMEM medium (PanEko, Russia), 10\% fetal bovine serum (PAA, Austria), glutamine $(0.65 \mathrm{mg} / \mathrm{mL}$, PanEko, Russia), and gentamycin $(50 \mu \mathrm{g} / \mathrm{mL}$, PanEko, Russia). After establishing the neutral values of $\mathrm{pH}$, the plates with examined samples and without them (control with cultural plastic, polystyrene) were introduced with a cell suspension (the
MG-63 culture at a density of 7000 cells per well) at $200 \mu \mathrm{L}$ of the CGM, which was incubated for 1, 3, and 7 days with regular replacements of the CGM. All of the procedures were performed under sterile conditions in an atmosphere of moist air that contained $5 \% \mathrm{CO}_{2}$ at $37^{\circ} \mathrm{C}$. The viability of MG-63 cell lines over time was assessed using an MTT test, which is based on the ability of dehydrogenase of living cells to reduce 3-(4,5dimethyl-2-thiazolyl)-2,5-diphenyl-2h-tetrazolium bromide (MTT) into formazan. The amount of formazan formed that is estimated spectrophotometrically (Thermoscientific, $\lambda=540$ $\mathrm{nm}$ ) describes proliferative activities (viability and amount) of different human and animal cells. ${ }^{35}$ The pool of viable cells (PVC) was evaluated at different stages of the experiment as a ratio of the optical density of formazan solution (MTT reaction product) on a certain day of the experiment (1,3, and 7 days) to the optical density in control. A specimen was assumed to be cytocompatible in the absence of cytotoxicity (PVC $\geq 70 \%$ ) on a certain day of cultivation. Additionally, for cytocompatible samples, the increase in cell population (with respect to the first day of cultivation) was assessed.

The obtained results were processed by conventional methods of variational statistics using Microsoft Excel 2000. The significance of differences was assessed using a parametric Student $t$-test; differences were considered statistically significant at $p<0.05$.

\section{RESULTS AND DISCUSSION}

3.1. Powder Properties. Data on $\mathrm{Al}$ content in the investigated species are presented in Table 1, which shows that the chemical composition of synthesized materials is close to the predetermined one. According to the XRD analysis, the powders consist of only the hydroxyapatite (JCPDS \#09-432) phase with a low crystallinity degree (Figure 1). We did not

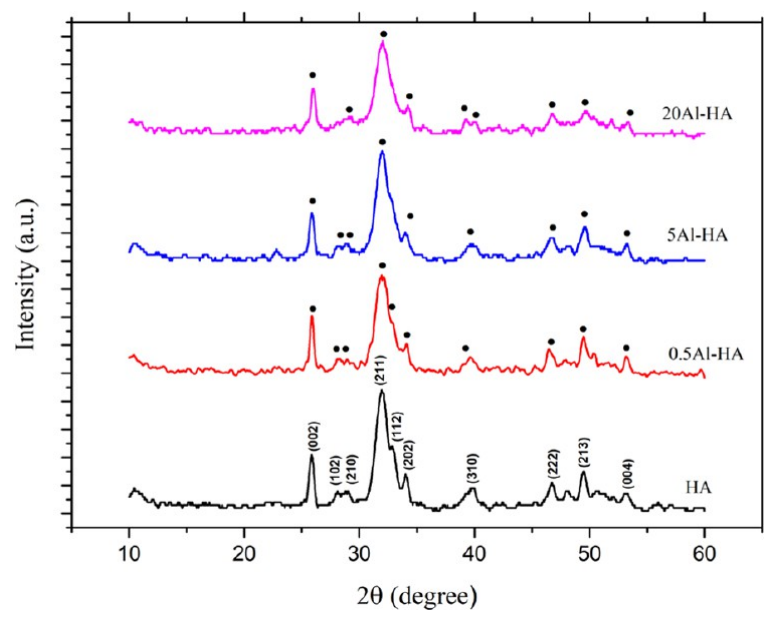

Figure 1. XRD spectra of Al-HA powders. • - HA (JCPDS No. 09-432).

observe the formation of other phases in the case of even high $\mathrm{Al}$ substitution in contrast to the data of Kaygili et al., who demonstrated that the formation of $\mathrm{AlPO}_{4}, \mathrm{CaP}_{4} \mathrm{O}_{11}$, $\mathrm{Al}_{3}\left(\mathrm{PO}_{4}\right)_{2}(\mathrm{OH})_{3}\left(\mathrm{H}_{2} \mathrm{O}\right)_{5}$, and $\mathrm{Ca}_{2} \mathrm{Al}\left(\mathrm{PO}_{4}\right)_{2}(\mathrm{OH})$ started from $10 \%$ Al-doped HA obtained by sol-gel synthesis. Kolekar et al. demonstrated the formation of $\mathrm{HA}$ and $\mathrm{Al}_{2} \mathrm{O}_{3}$ for $0.5-2.5 \mathrm{~mol} \%$ $\mathrm{Al}$-substituted powders obtained by modifying the solution combustion method. ${ }^{6}$ Wang et al. ${ }^{10}$ demonstrated the presence of the only apatite phase in the case of $2.78 \mathrm{wt} \%$ of $\mathrm{Al}$ substitution, but further increase of $\mathrm{Al}$ amount resulted in the 
formation of impurity phases of $\mathrm{CaHPO}_{4}, \mathrm{AlPO}_{4}$, and $\mathrm{Ca}_{3}(\mathrm{PO} 4)_{2}$ in the case of the predicted $\mathrm{Al}$ content of $5.56 \mathrm{wt}$. $\%$. So, we should focus on the entry of the whole amount of introduced $\mathrm{Al}$ in the lattice of synthesized $\mathrm{Al}-\mathrm{HA}$ in the case of the coprecipitation method according to XRD in the present work. Synthesis of the $20 \mathrm{~mol} \% \mathrm{Al}$-substituted HA structure without other impurity phases is reported for the first time to the best of the authors' knowledge.

We observed a sharp decrease of the diffractogram resolution: the shape of the triplet between 30.5 and $33.5^{\circ}$ of Al-HA samples became smoother with the introduction of $\mathrm{Al}$, and the peaks shifted to larger angle areas. Parameters $a$ and $c$ were calculated as a function of the $\mathrm{Al}$ content, and the results are presented in Table 1 . The monotonous decrease of cell parameters $a$ and $c$ is observed. It is due to lower ionic radii for $\mathrm{Al}^{3+}$ compared with $\mathrm{Ca}^{2+}(0.051$ and $0.104 \mathrm{~nm}$, respectively $) .{ }^{17}$ The data of the calculation of $D$ is reported in Table 1 . The slight decrease of crystalline size with the growth of $\mathrm{Al}^{3+}$ content is also demonstrated.

In Figure 2, the FTIR spectra typical for HA are shown. ${ }^{36}$ The sharp peak at $3570 \mathrm{~cm}^{-1}$ corresponds to the stretching vibration

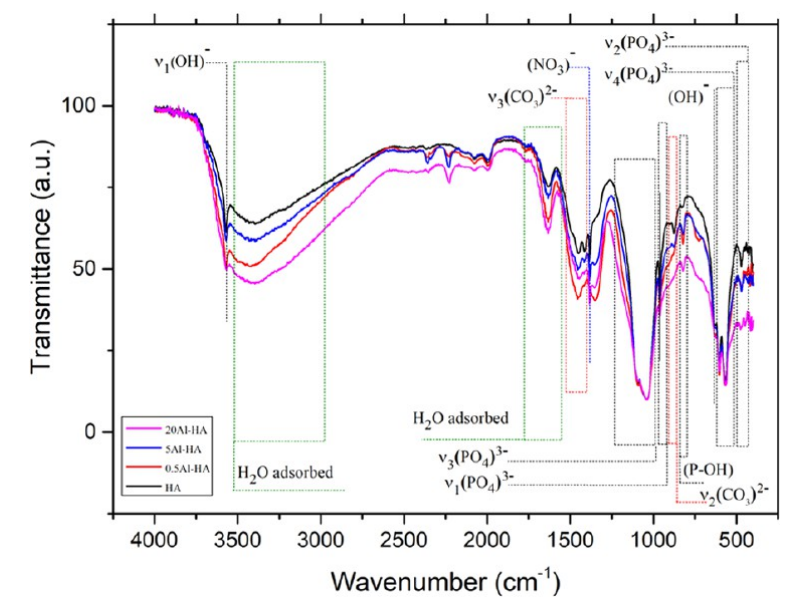

Figure 2. FTIR spectra of Al-HA powders.

of $\mathrm{OH}^{-}$, and a vibrational band of $\mathrm{OH}^{-}$at $635 \mathrm{~cm}^{-1}$ gradually decreases in intensity with the increase of $\mathrm{Al}$ amount. These data correlate to the results of Wakamura et al. ${ }^{19}$ and indicate the lattice deformation of $\mathrm{HA}$ with $\mathrm{Al}$ incorporation. One can also notice a decrease in the depth of adsorbed $\mathrm{H}_{2} \mathrm{O}$ broad regions at 2900-3400 and 1780-1525 $\mathrm{cm}^{-1}$. The phosphate groups present a doublet at 570 and $600 \mathrm{~cm}^{-1}$ arising from the $\mathrm{P}-\mathrm{O}$ bending mode $\nu_{4}$; the broad triplet at $420-480 \mathrm{~cm}^{-1}$ was attributed to the doubly generate bending mode $\nu_{2}$.

The stretching vibration of the $\nu_{1}$ phosphate group peak at $962 \mathrm{~cm}^{-1}$ decreases in intensity with the increase of $\mathrm{Al}^{3+}$ substitution, and the peak at $875 \mathrm{~cm}^{-1}$ disappears for $20 \mathrm{~mol}$ $\% \mathrm{Al}$ (Figure 3a,b). The intensity of deformations of $\mathrm{P}-\mathrm{OH}$ groups of $\mathrm{HPO}_{4}{ }^{2-}$ ions increases with the growth of $\mathrm{Al}^{3+}$ content at $820 \mathrm{~cm}^{-1}$ (Figure 3c). ${ }^{37}$ The stretching vibration mode of the phosphate group $\nu_{3}$ presents a doublet at 1050 and $1100 \mathrm{~cm}^{-1}$. Nitrate residues from reactants are detected as bands at 1380 $\mathrm{cm}^{-1} \cdot{ }^{38}$ This nitrate group can be used as a precursor for a stable radiation-induced radical for EPR and ENDOR investigations ${ }^{39}$ described in the next section. The doublet at $1410-1540 \mathrm{~cm}^{-1}$ corresponds to the vibration mode $\nu_{3}$ of $\mathrm{CO}_{3}{ }^{2-}$ absorbed from the air and becomes smoother and decreases in intensity with $\mathrm{Al}^{3+}$ content. $^{40}$

FEG SEM data demonstrate the formation of powder agglomerates formed by nanoparticles for all synthesized species (Figure 4). Pure HA powder consists of predominately spherical and uniaxial particles with average sizes of 50-100 nm.

The introduction of $\mathrm{Al}$ results in the formation of uniaxial crystals with a width of $10-20 \mathrm{~nm}$ and length of $30-40 \mathrm{~nm}$. The growth of $\mathrm{Al}$ content leads to the appearance of prismatic powders with an average length of $100-150 \mathrm{~nm}$ for 5Al-HA. Needlelike crystals with length of $100-250 \mathrm{~nm}$ are formed for 20Al-HA powders. Thus, doping of $\mathrm{HA}$ by $\mathrm{Al}$ provokes the formation of a highly anisotropic phase.

According to TEM data, the particles of HA powders were predominantly round-shaped with an average radius of $30 \mathrm{~nm}$ (Figure 5). 0.5Al-HA consists of uniaxial and irregular-shaped particles with a size of $30-50 \mathrm{~nm}$ (Figure $5 \mathrm{~b}$ ). In agreement with SEM data, an increase of $\mathrm{Al}$ content resulted in the formation of prismatic particles, and needlelike and prismatic particles were observed for 5Al-HA and 20Al-HA samples with changes of length from $70-80$ to $100-150 \mathrm{~nm}$ with $\mathrm{Al}$ growth. The similar shape evolution of HA particles as-synthesized by the precipitation method with substitution up to $10 \mathrm{~mol} \%$ of $\mathrm{Al}$ has been described in ref 20 .

The images of mapping obtained by the XEDS analyzer demonstrate the distribution of elements in powders (Figure 6). Pure HA is formed by Ca, $\mathrm{P}$, and $\mathrm{O}$. The introduction of $0.5 \mathrm{~mol}$

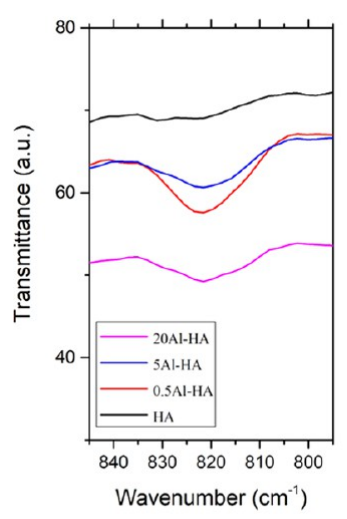

(a)

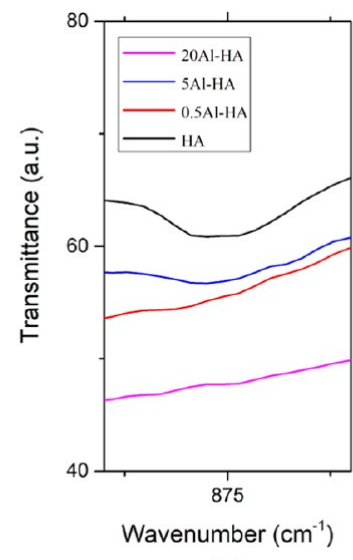

(b)

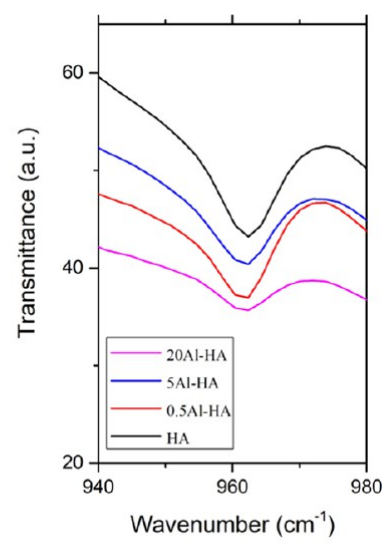

(c)

Figure 3. Influence of $\mathrm{Al}^{3+}$ content on the intensity of $\nu_{1}$ of the $\mathrm{PO}_{4}{ }^{3-}$ group (a, b) and the $\mathrm{P}-\mathrm{OH}$ group of $\mathrm{HPO}_{4}{ }^{2-}$ ions $(\mathrm{c})$. 


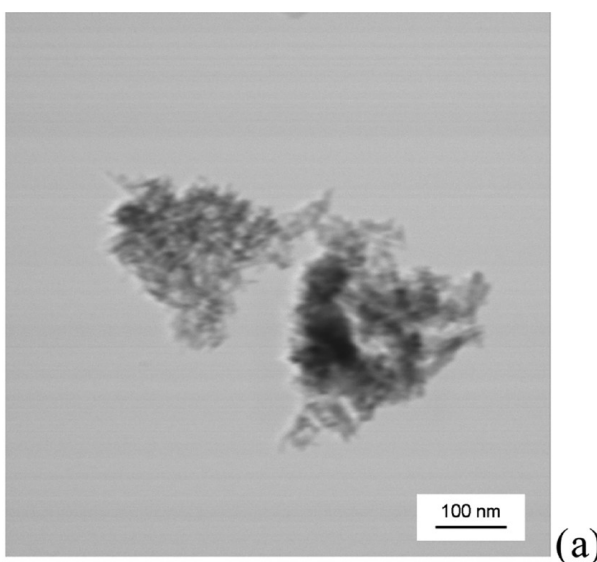

(a)

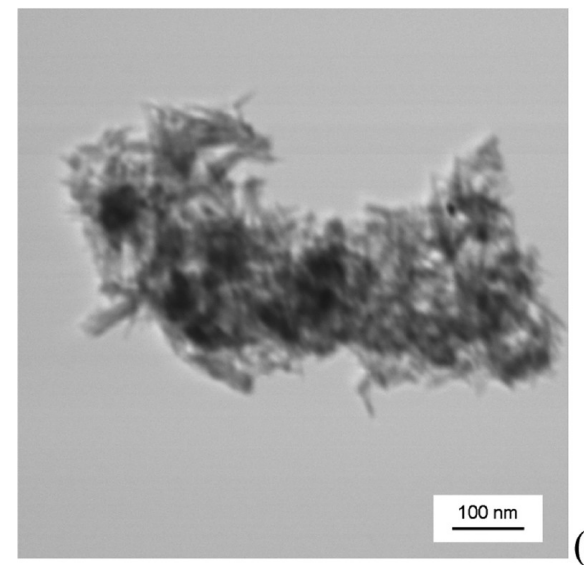

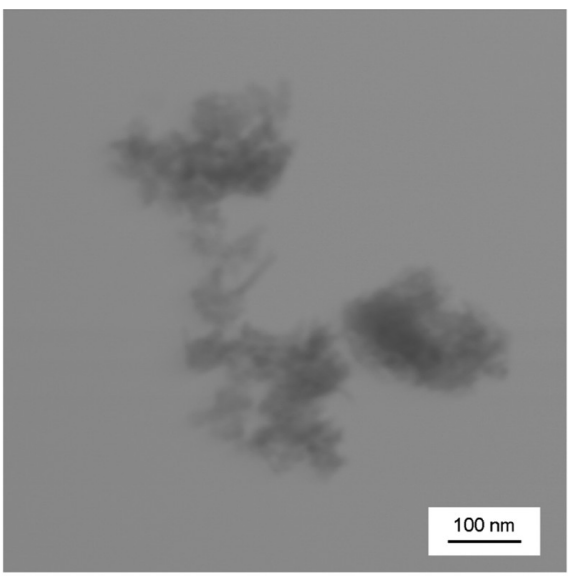

(b)

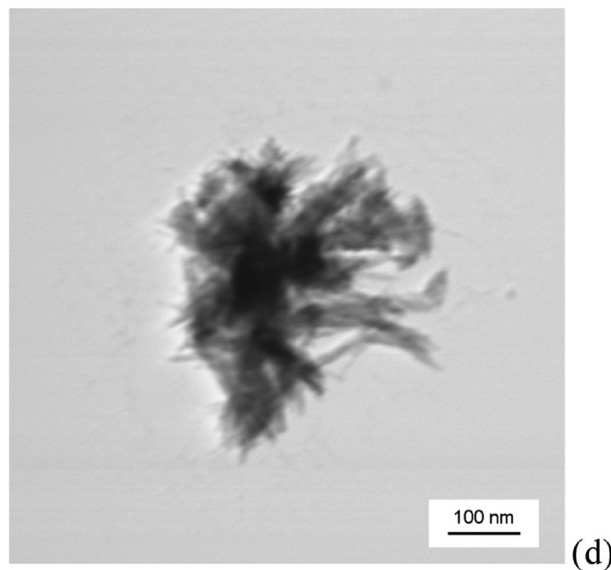

Figure 4. TEM data of HA (a) and Al-HA samples, with 0.5 (b), 5 (c), and 20 (d) mol \% of Al.

$\%$ of $\mathrm{Al}$ resulted in the appearance of feeble signals of $\mathrm{Al}$. The increase of $\mathrm{Al}$ content leads to an intensification of the $\mathrm{Al}$ signal and decrease of the Ca signal density. We did not observe any anomalous zones of $\mathrm{Al}$ distribution linked with the presence of the shell-core structure or the appearance of Al-enriched phases. It confirms the results of XRD analysis and evidences the formation of Al-substituted HA.

3.2. EPR and ENDOR Studies. Figure 7 shows the EPR spectra of pure HA and 20Al-HA in the X-band. The samples contain paramagnetic impurities in low concentration that can be estimated (from the sensitivity limit of our equipment) as $C<$ $10^{15} \mathrm{spin} / \mathrm{g}$ and ascribed to the carbonate radical $\mathrm{CO}_{2}{ }^{-}$(see refs $41,42)$. The authors of the mentioned papers indicate the possibility of the existence of an isotropic signal from $\mathrm{CO}_{2}{ }^{-}$with $g$-factor in the range of 2.007-2.008 and an anisotropic one (corresponding to $C_{2 v}$ symmetry) with $g_{1}=2.0030 ; g_{2}=2.0015$; $g_{3}=1.997$. Thus, the EPR signal in "pure" HA is most likely due to the anisotropic signal from $\mathrm{CO}_{2}{ }^{-}$with rotation around the $\mathrm{O}-\mathrm{O}$ axis so that the values of $g_{1}$ and $g_{2}$ are averaged.

As seen from Figure 7, aluminum introduction reduces the intensity of the native EPR signal to the spectrometer noise level. In ref 31 , an inverse correlation between the levels (concentrations) of the nitrogen-centered impurity $\mathrm{NO}_{3}{ }^{-}$ centers and carbonate anions was shown. It was explained by the "displacement" of $\mathrm{NO}_{3}{ }^{-}$impurity centers from the phosphate positions. It is difficult to determine directly from EPR experiments the mechanism by which the introduction of the aluminum cation would lead to a decrease in the concentration of carbonate anions. The following schemes can be proposed.

(1) A decrease in the crystallinity of the samples with the introduction of aluminum (according to XRD data) leads to a complete averaging of the anisotropy of the $g$-factors of $\mathrm{CO}_{2}{ }^{-}$and higher variations of the crystal field parameters. This leads to a broadening of the EPR signal and the impossibility of its detection against the noise level.

(2) It is known that carbonate radicals can occupy the position of $\mathrm{OH}$ groups and phosphates in the structure of apatites ( $\mathrm{A}$ and $\mathrm{B}$ types of substitutions, respectively ${ }^{42,43}$ ). When aluminum is introduced, additional introduction of $\mathrm{OH}$ groups is possible, leading to the displacement of carbonate groups from $\mathrm{OH}$ channels.

(3) According to the data of ref 44, a part of aluminum in apatite structures at high concentrations can replace positions of phosphorus, which in turn can also lead to the reduction of B-type carbonates.

(4) The introduction of aluminum causes an increase of the proton-containing groups $(\mathrm{HOH}, \mathrm{OH}, \mathrm{H})$, which, as is well known, enhances the rate of recombination of radicals. Therefore, the amount of $\mathrm{CO}_{2}^{-}$also decreases.

X-band EPR spectra for pure HA and 20Al-HA samples after irradiation are presented in Figure 8 . These signals are due to the stable nitrogen radicals $\mathrm{NO}_{3}{ }^{2-}$, which has one unpaired electron. Accordingly, this center has an electron spin $S=1 / 2$. Nitrogen $\left({ }^{14} \mathrm{~N}\right)$ present in this radical possesses nuclear spin $I=1$. 


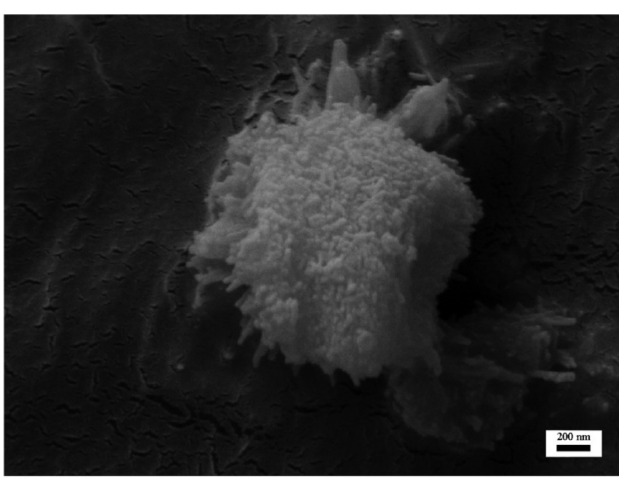

(a)

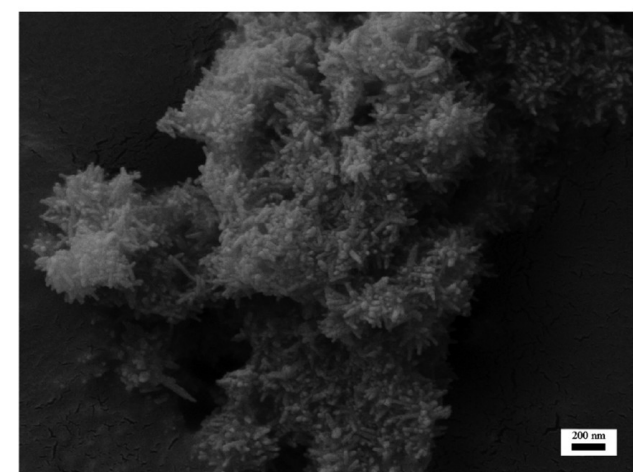

(c)

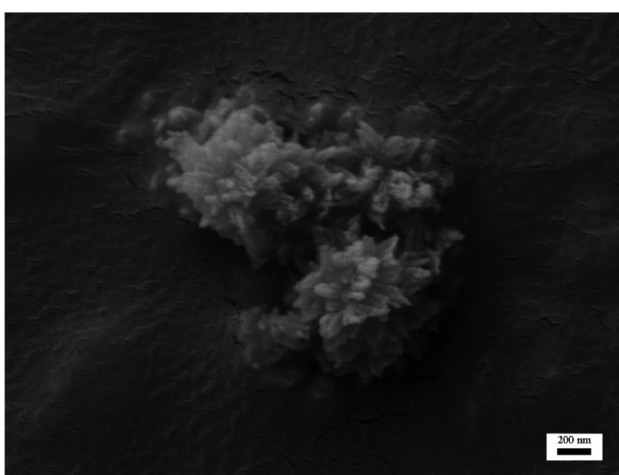

(b)

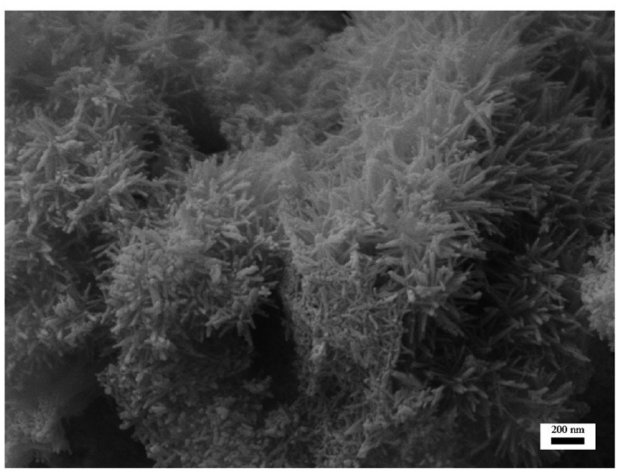

(d)

Figure 5. Morphology of HA (a) and Al-HA samples, with 0.5 (b), 5 (c), and 20 (d) mol \% of Al for the $200 \mathrm{~nm}$ scale.

Consequently, an unpaired electron magnetic moment of the $\mathrm{NO}_{3}{ }^{2-}$ radical interacts with the magnetic moment of the nitrogen nucleus (hyperfine interaction, HF), which leads to the presence of additional splitting of the HF structure in the EPR spectrum and characterized by an HF constant denoted A.

$\mathrm{HF}$ interaction is anisotropic, that is, it depends on the orientation of the molecule relative to the external magnetic field. The EPR spectra of the samples are described by the spin Hamiltonian of axial symmetry for $S=1 / 2$ and $I=1$. A detailed description of the EPR spectra of nitrogen-centered radicals with calculations in the framework of DFT models is given in ref 24. Figure 9 shows the corresponding spectra simulations for HA and 20Al-HA in both X-and W-bands with the parameters given in Table 2. Comparison of the obtained spectroscopic parameters with literature data $^{24}$ suggests that the stable $\mathrm{NO}_{3}{ }^{2-}$ radicals are localized in phosphate positions with charge compensation in the form of the vacant position of the nearest calcium ion. Their concentration for the chosen irradiation dose can be estimated as $8(1) \cdot 10^{18}$ spins $/ \mathrm{g}$.

In addition to the nitrogen radicals after irradiation, in the studied samples a signal with $g \approx 2.014(3)$ in the X-band spectra is detected (Figure 9a). There is no consensus in the literature about the exact nature of this signal. Most often it is attributed to the carbonate radical $\mathrm{CO}_{3}{ }^{-}$, formed from the nonparamagnetic $\mathrm{CO}_{3}{ }^{2-}$ by capturing a hole. ${ }^{42}$ With an increase in the aluminum concentration, the intensity of this signal remains almost unchanged. Apparently, the introduction of an $\mathrm{Al}$ ion with an excess positive charge of $3+$ should contribute to an increase in the number of $\mathrm{CO}_{3}{ }^{-}$radicals. However, the mechanisms described above for reducing the total amount of carbonate radicals with the introduction of aluminum ions probably lead to the observed experimental fact that the number of implanted cations has a weak effect on the signal with $g \approx 2.014$.

In a number of our previous works, it was shown that the spectroscopic and relaxation parameters of the stable $\mathrm{NO}_{3}{ }^{2-}$ radicals in various calcium phosphates are extremely sensitive to changes in their local environment like the introduction of cations and anions, the transition from microsize to nanoscale samples, the phase transition to other types of calcium phosphate, etc. ${ }^{31,32,46-48}$ This allows the use of $\mathrm{NO}_{3}{ }^{2-}$ as a sensitive paramagnetic probe. In this paper, we decided to trace how the introduction of a nonparamagnetic trivalent aluminum cation affects the EPR characteristics of this probe.

EPR parameters (components of $g$ - and $A$-tensors) in both Xand $\mathrm{W}$-bands practically do not change with $\mathrm{Al}^{3+}$ doping (Table 2). Relaxation times $T_{2 \mathrm{e}}$ and $T_{1 \mathrm{e}}$ were measured in the $\mathrm{W}$-band at room temperature in perpendicular $B_{\perp}$ and parallel $B_{\|}$ orientations (the $B$ values were chosen for the corresponding pure parallel and perpendicular orientations of the external magnetic field with respect to the main axes of the $g$-tensor of the nitrogen-centered radical; see Figure $9 \mathrm{~b}$ and paper 24). The resulting decay/recovery curves were approximated by singleexponential functions with $T_{1}=(25-37) \mu$ s and $T_{2}=(1.6-3.0)$ $\mu \mathrm{s}$, almost independent of the chosen orientation and concentration of aluminum cations. Thus, the introduction of aluminum does not lead to the appearance of additional relaxation mechanisms for $\mathrm{NO}_{3}{ }^{2-}$ in contrast to the doping with the paramagnetic manganese $\mathrm{Mn}^{2+}$ ions. ${ }^{46,47}$ Therefore, it can be concluded that in the case of $\mathrm{Al}^{3+}$ cations and $\mathrm{NO}_{3}{ }^{2-}$ anions codoping, the ions are positioned far away from each other to influence the $\mathrm{NO}_{3}{ }^{2-}$ surrounding. 

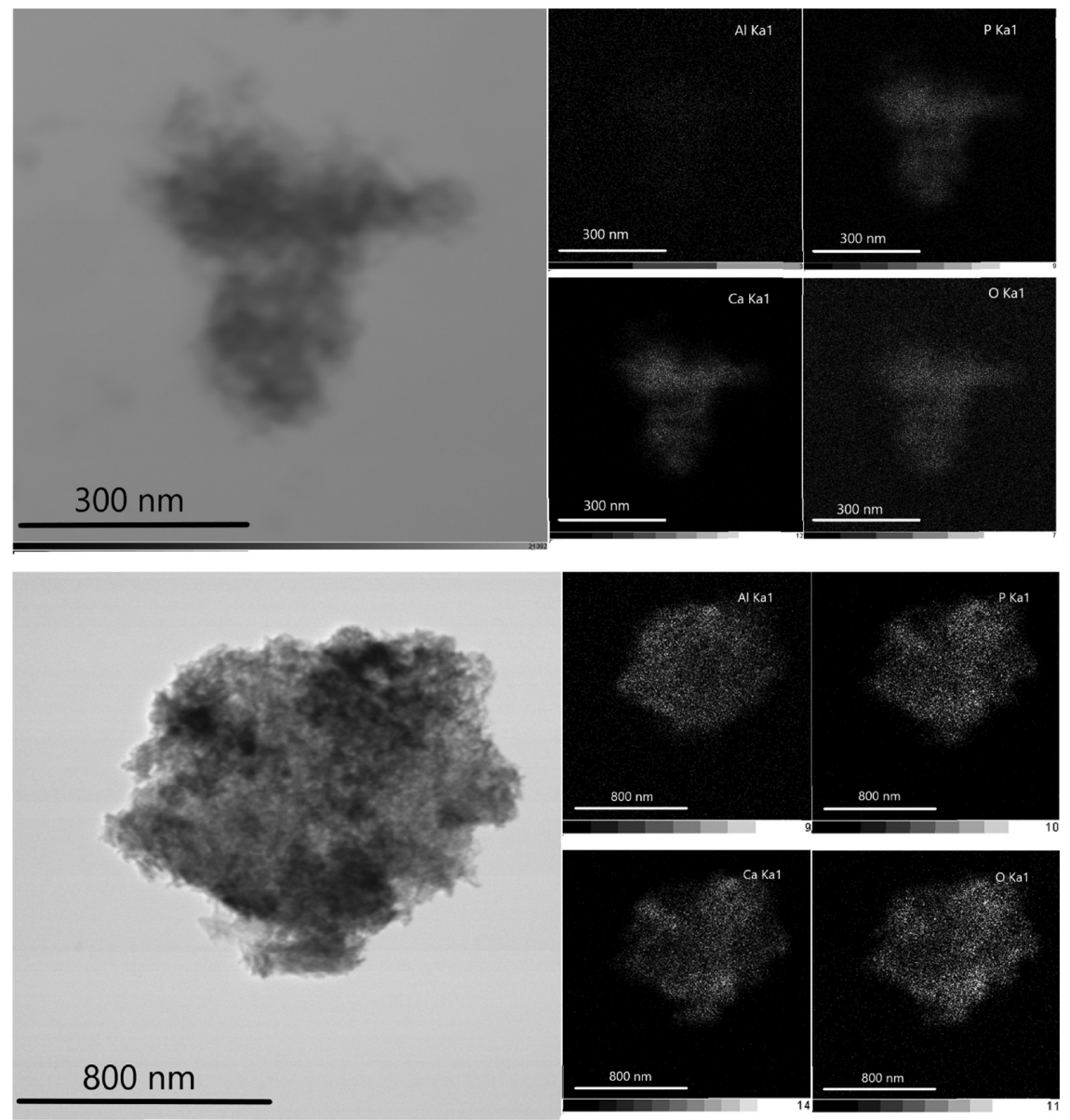

Figure 6. Comparison of TEM and EDS images between HA (upper panel) and 20Al-HA (lower panel) samples.

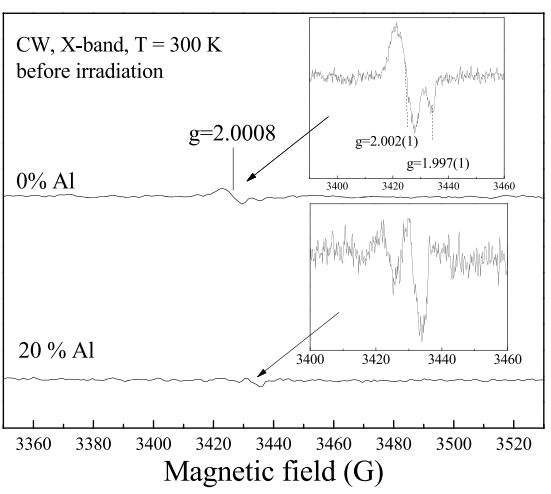

Figure 7. Continuous wave X-band EPR spectra at $T=300 \mathrm{~K}$ for pure $\mathrm{HA}$ and 20Al-HA samples. Insets show the normalized detailed spectra in the vicinity of the obtained EPR signals.

For the same magnetic fields $B_{\perp}$ and $B_{\|}$Mims ENDOR spectra in the $\mathrm{W}$-band at $T=50 \mathrm{~K}$ for protons $\left({ }^{1} \mathrm{H}, I=1 / 2\right)$ and phosphorous $\left({ }^{31} \mathrm{P}, I=1 / 2\right)$ were measured. Figure 10 presents the ${ }^{31} \mathrm{P}$ ENDOR at the Larmor frequency of phosphorus. The magnitudes of the superhyperfine splittings are given in Tables 3 and 4 . They coincide with the data of ref 24 , corresponding to the localization of the nitrogen-centered radical in the $B$ position. It can be seen that the introduction of aluminum impurities does not affect ${ }^{31} \mathrm{P}$ ENDOR.

Figure 11 presents the ENDOR spectra at the Larmor frequency of protons. In pure $\mathrm{HA}$, as well as for phosphorus nuclei, the type of spectra and the magnitude of the splitting

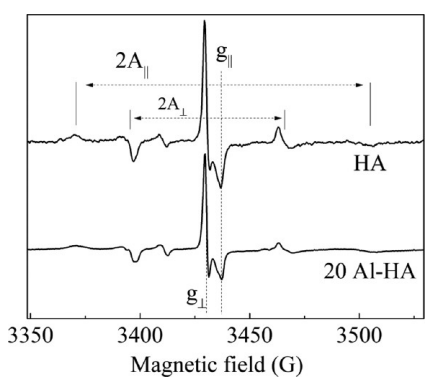

Figure 8. Continuous wave X-band EPR spectra at $T=300 \mathrm{~K}$ for pure HA and 20Al-HA samples after X-ray irradiation. $g$ - and $A-$ components are marked.

correspond to the data listed in refs 24,39 and are determined by the set of hydrogen protons closest to the $\mathrm{NO}_{3}{ }^{2-}$ radical. The introduction of aluminum impurities does not change the given splitting values. For the spectrum of pure $\mathrm{HA}$ and with the maximum concentration of aluminum impurity, the values of the superhyperfine splittings remain the same. Consequently, the closest environment of the nitrogen radical does not change. However, as the aluminum concentration increases, the signal at the center of the spectra (at the Larmor frequency of the protons) increases in intensity for both values of the external magnetic field.

Figure 12 shows the difference ENDOR spectrum - the ENDOR spectrum of a sample with $20 \% \mathrm{Al}$ is subtracted from the ENDOR spectrum of a "pure" $\mathrm{HA}$ sample for ${ }^{1} \mathrm{H}$ in for $B_{\perp}$. The difference ${ }^{1} \mathrm{H}$ ENDOR spectrum can be well described by 

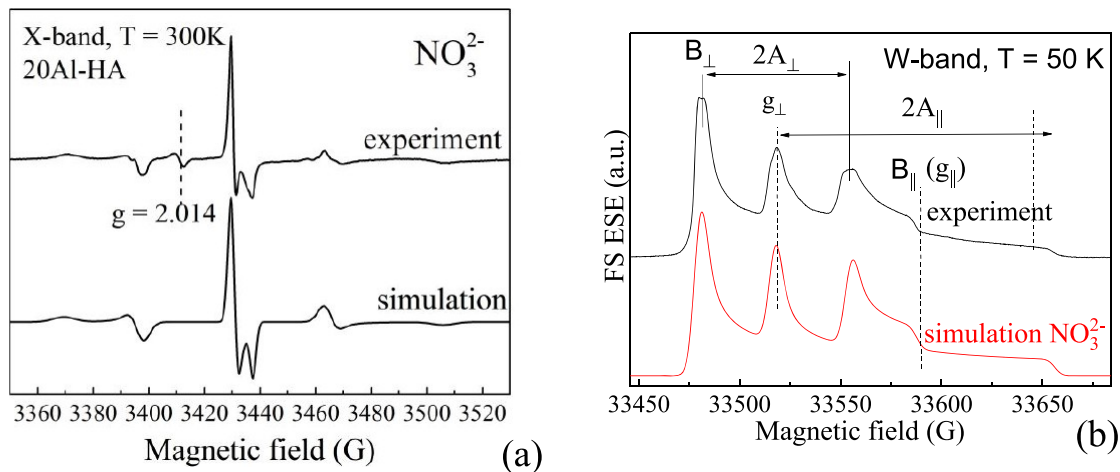

(a)

Figure 9. (a) Experimental and simulated X-band cw EPR spectra for the irradiated 20Al-HA sample with the parameters of simulation given in Table 2. (b) Experimental and simulated W-band pulsed EPR spectra detected at $T=50 \mathrm{~K}$ for the irradiated HA sample with the parameters of simulations given in Table 2. Electronic relaxation times and ENDOR spectra were measured in magnetic fields $B_{\perp}$ and $B_{\|}$shown in the (b) panel.

Table 2. Parameters for the Simulation of the NitrogenCentered Species in Al-HA Samples for Both Frequency Ranges (X-and W-Bands)

\begin{tabular}{ccccr}
$\begin{array}{c}\mathrm{Al} \\
\text { content } \\
(\%)\end{array}$ & $g_{\|}$ & $g_{\perp}$ & $A_{\|}(\mathrm{MHz})$ & \multicolumn{1}{c}{$A_{\perp}(\mathrm{MHz})$} \\
0 & $2.0018(4)$ & $2.0061(3)$ & $190(6.8 \mathrm{mT})$ & $103.7(3.7 \mathrm{mT})$ \\
0.5 & $2.0019(4)$ & $2.0059(3)$ & $193(6.9 \mathrm{mT})$ & $105.8(3.8 \mathrm{mT})$ \\
5 & $2.0018(4)$ & $2.0060(3)$ & $192(6.85 \mathrm{mT})$ & $101(3.6 \mathrm{mT})$ \\
20 & $2.0018(4)$ & $2.0061(3)$ & $190(6.8 \mathrm{mT})$ & $103.4(3.7 \mathrm{mT})$ \\
\hline
\end{tabular}
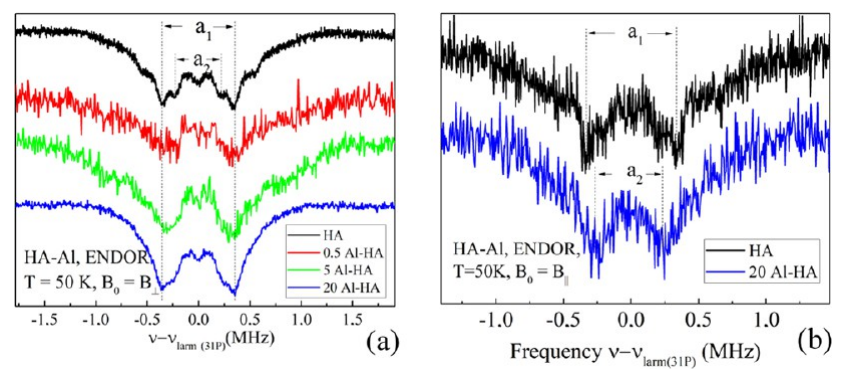

Figure 10. W-band ENDOR spectra in the vicinity of Larmor frequency of ${ }^{31} \mathrm{P}$ for the perpendicular (a) and parallel (b) magnetic fields (cf. Figure $9 \mathrm{~b})$. Values of $a_{1}$ and $a_{2}$ are given in Table 3 .

Table 3. Experimental Values of ENDOR Splittings (in MHz) for ${ }^{31} \mathbf{P}$ (See Figure 10)

\begin{tabular}{lll} 
& $B_{0}=B_{\perp}$ & $B_{0}=B_{\|}$ \\
$a_{1}$ & $0.69(2)$ & $0.68(3)$ \\
$a_{2}$ & $0.47(2)$ & $0.51(4)$ \\
\hline
\end{tabular}

Table 4. Experimental Values of ENDOR Splittings (in MHz) for ${ }^{1} \mathrm{H}$ (See Figure 11)

\begin{tabular}{lll} 
& $B_{0}=B_{\perp}$ & $B_{0}=B_{\|}$ \\
$a_{1}$ & $1.03(4)$ & $1.00(6)$ \\
$a_{2}$ & $0.76(3)$ & $0.36(5)$ \\
$a_{3}$ & $0.57(3)$ & \\
$a_{4}$ & $0.31(2)$ & \\
\hline
\end{tabular}

the Lorentzian shape of the curve with the FWHM $\Delta \nu=0.21$ MHz. If we take the point-dipole model to describe the interaction of electron and nuclear spins, we can estimate the corresponding average distance between the hydrogen and the nitrogen radical as $r=0.72 \mathrm{~nm}$. Thus, the introduction of
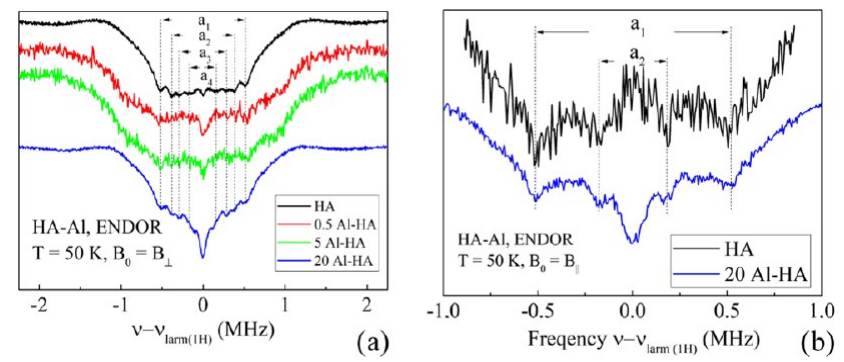

Figure 11. W-band ENDOR spectra in the vicinity of Larmor frequency of ${ }^{1} \mathrm{H}$ for the perpendicular (a) and parallel (b) magnetic fields (cf. Figure $9 \mathrm{~b})$. Values of $a_{1}-a_{4}$ are listed in Table 4.

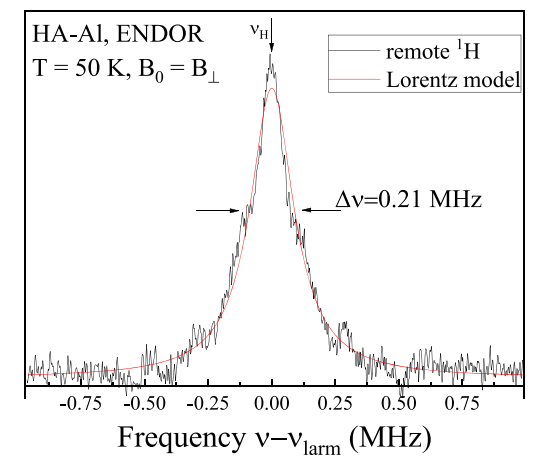

Figure 12. Difference ${ }^{1} \mathrm{H}$ ENDOR spectrum (the ENDOR spectrum for the sample with $20 \% \mathrm{Al}$ is subtracted from the ENDOR spectrum for the sample of pure HA) in the region of the Larmor frequency of hydrogen and its fitting with the Lorentz curve.

aluminum leads to an increase in the number of protons in the distant environment (remote protons) of the nitrogen radical, located at a distance of approximately $0.72 \mathrm{~nm}$ and farther on. This is consistent with the literature data on the $\mathrm{FTIR}^{20}$ on the increase in the number of protic groups with the introduction of aluminum and the above-mentioned arguments.

3.3. DFT Results. To provide an atomic scaled insight into the effects of positional reorganization and deformation of the $\mathrm{HA}$ crystal upon $\mathrm{Al}$ inclusion, the DFT calculations were performed. With regard to the aluminum impurity inclusion in $\mathrm{HA}$, when $\mathrm{Al}^{3+}$ replaces $\mathrm{Ca}^{2+}$, two possible schemes of charge compensation were considered. In the first scheme, the replacement of two $\mathrm{Ca}^{2+}$ ions by two $\mathrm{Al}^{3+}$ ions is accompanied by the creation of a $\mathrm{Ca}^{2+}$ vacancy. In the second scheme, for each $\mathrm{Al}^{3+}$ introduced in the $\mathrm{Ca}^{2+}$ position, the loss of one proton 
belonging to the hydroxide ion maintains the electroneutrality of the crystal. An alternative scheme of the introduction of $\mathrm{Al}$ in $\mathrm{HA}$, when $\mathrm{Al}$ substituted the $\mathrm{P}$ atom in orthophosphate, was proposed in. ${ }^{44,45} \mathrm{We}$ did not succeed in the geometry optimization of the latter scheme; thus, in the present work, we consider only the cases when the $\mathrm{Al}^{3+}$ substitutes the calcium cation.

In the unit cell, overall three combinations of two aluminum positions could be achieved, when the impurity takes the place of calcium in $\mathrm{Ca}(\mathrm{I}) / \mathrm{Ca}(\mathrm{I}), \mathrm{Ca}(\mathrm{I}) / \mathrm{Ca}(\mathrm{II})$, and $\mathrm{Ca}(\mathrm{II}) / \mathrm{Ca}$ (II) positions. The Ca vacancy formation was assumed to be in one of the closest to $\mathrm{Al}^{3+}$ positions. The averaged energy values for every type of inclusion are given in Table 5. From this, one can

\section{Table 5. Calculated Energy of the Pure HA Cell and That Codoped with $\mathrm{Al}^{3+}$ Ions}

$\begin{array}{ll}\text { crystal structure } & \text { total energy, Ry } \\ \text { pure } \mathrm{HA} & -3336.625 \\ \mathrm{HA} \text { doped at Ca vacancy formation } & \\ \mathrm{Ca}(\mathrm{I}) / \mathrm{Ca}(\mathrm{I}) & -3136.608(0.013) \\ \mathrm{Ca}(\mathrm{I}) / \mathrm{Ca}(\mathrm{II}) & -3136.647(0.02) \\ \mathrm{Ca}(\mathrm{II}) / \mathrm{Ca}(\mathrm{II}) & -3136.656(0.017) \\ \mathrm{HA} \mathrm{doped} \mathrm{at} \mathrm{H}^{+} \text {vacancy formation } & \\ \mathrm{Ca}(\mathrm{II})^{a} & -3209.290 \\ \mathrm{Ca}(\mathrm{II})^{b} & -3209.348\end{array}$

${ }^{a}$ Location in the same anion channel. ${ }^{b}$ Location in different anion channels. The standard deviation values are given in parentheses.

conclude that the substitution in the $\mathrm{Ca}$ (II)/Ca(II) position is the most energetically favorable, the $\mathrm{Ca}(\mathrm{I}) / \mathrm{Ca}(\mathrm{II})$ position is less favorable but still comparable with $\mathrm{Ca}(\mathrm{II}) / \mathrm{Ca}$ (II), and the $\mathrm{Ca}(\mathrm{I}) / \mathrm{Ca}(\mathrm{I})$ position has statistically the least energy values. These observations point out the preferable location of aluminum ions in the anion channel and are in agreement with the data obtained by Wang and coauthors, obtained for the hexagonal $\mathrm{HA}$ cell. ${ }^{10}$ For the second scheme of charge compensation, two $\mathrm{Al}^{3+}$ ions were introduced in $\mathrm{Ca}$ (II) positions in the same anion channel and in two different anion channels. The introduction leads to the release of two $\mathrm{H}^{+}$from the hydroxide ions, which are positionally the closest to the aluminum ions. A notable energy benefit was observed when $\mathrm{Al}^{3+}$ ions were placed in the different channels. The most energy favorable geometries are shown in Figure 13. These findings agree well with the XEDS experimental observations of the present work about the rather even distribution of aluminum ions over the HA crystal than in a locally concentrated manner, which, in turn, is in agreement with the results of Wang et al. ${ }^{10}$

Despite a rather slight distortion of the lattice, the introduction of $\mathrm{Al}^{3+}$ leads to a notable reorganization of its surrounding. Both orthophosphate and hydroxide ions (or $\mathrm{O}^{2-}$ ion depending on the charge compensation scheme) tend to bring their oxygen atoms closer to the aluminum position. As a result, up to four oxygen atoms within the coordination sphere of $\mathrm{Al}^{3+}$ are placed at the distance of $1.9-2.0 \AA$, while for $\mathrm{Ca}^{2+}$ this distance amounts to $2.3-2.5 \AA$. The structural reorganization in the $\mathrm{HA}$ cell is accompanied by a slight rotation of the $\mathrm{PO}_{4}$ molecule around the $\mathrm{P}$ center (the shift of $\mathrm{P}$ atoms is not larger than $0.2 \AA$ ). On the contrary, the positional displacement of the light $\mathrm{OH}^{-}$molecule toward the $\mathrm{Al}^{3+}$ position is quite large (by 0.6-0.7 $\AA$ ). It is worth noting that $\mathrm{Al}^{3+}$, having a smaller radius than $\mathrm{Ca}^{2+}$, tends to approach the orthophosphate molecules and to shift away from the anion channel retaining the $\mathrm{OH}^{-} / \mathrm{O}^{2-}$ ion (depending on the charge compensation scheme) in the bound state and, thus, distorts the geometry of the channel (Figure 13). The overall shift of $\mathrm{Al}^{3+}$ from the corresponding $\mathrm{Ca}^{2+}$ position is 0.8-0.9 A. Such a displacement of the $\mathrm{OH}^{-}$molecule inclines the $\mathrm{O}-\mathrm{H}$ bond from the anion channel axis (the angle $\mathrm{O}(\mathrm{H}) \cdots$ $\mathrm{O}$-H changes from 0 to $\sim 70^{\circ}$ ). These positional alterations can result in the changes of $\mathrm{OH}^{-}$vibrations detected by FTIR spectroscopy. Besides, the interactions between $\mathrm{Al}^{3+}$ and the oxygen atoms belonging to the orthophosphate and hydroxide ions lead to the redistribution of electron density and to the elongation of $\mathrm{O}-\mathrm{P}$ bonds. In turn, such a perturbation is expected to appear as a shift or broadening of the vibrational bands in the infrared spectrum.

To further extend the theoretical exploration of the experimental system studied, the $\mathrm{NO}_{3}{ }^{-}$ion (the precursor of the nitrate radical used for EPR as an intrinsic spin probe) was introduced to the $\mathrm{HA}$ cell containing $\mathrm{Al}^{3+}$. The nitrate molecule substituted the $\mathrm{PO}_{4}$ position (B-type) as it was detected to be more experimentally relevant than the substitution of the $\mathrm{OH}^{-}$ ion. ${ }^{24}$ Comparing a number of positional combinations, it was argued that the remote location of $\mathrm{NO}_{3}{ }^{-}$was more energetically favorable than its positioning in the proximity of $\mathrm{Al}^{3+}$. This could be due to the larger polarity of the $\mathrm{P}-\mathrm{O}$ bond than the $\mathrm{N}-\mathrm{O}$ bond, which results in more favorable interactions of aluminum with the orthophosphate ion than with the nitrate ion. The distant location of $\mathrm{Al}^{3+}$ and $\mathrm{NO}_{3}{ }^{-}$is also followed by the EPR study. As a comparison, EPR experiments and ab initio analysis
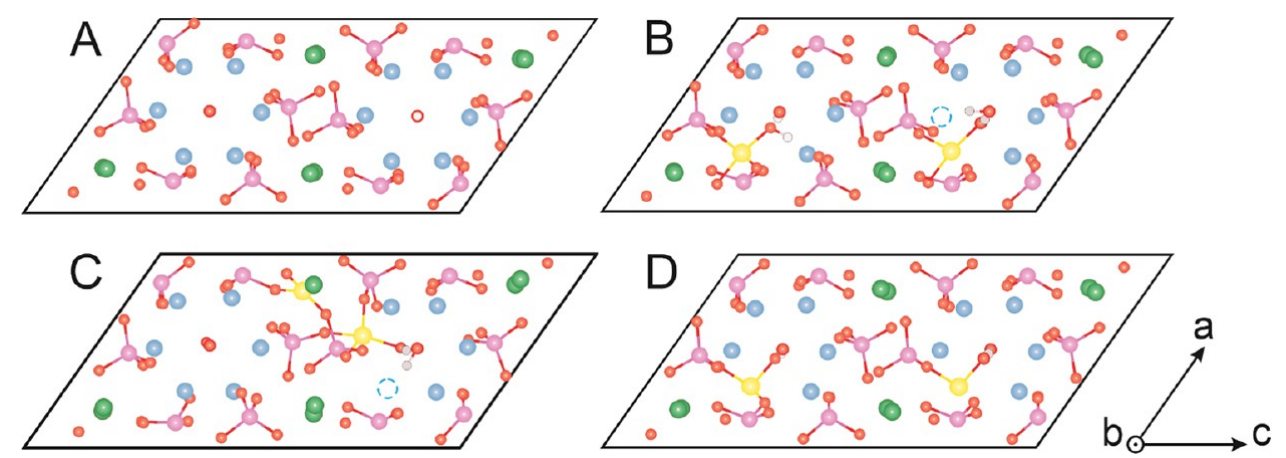

Figure 13. Optimized geometry of pure $\mathrm{HA}(\mathrm{A})$ and $\mathrm{HA}$ containing $\mathrm{Al}^{3+}$ impurity $(\mathrm{B}-\mathrm{D})$. The most energetically favorable inclusion of $\mathrm{Al}^{3+}$ ions in $\mathrm{Ca}(\mathrm{II}) / \mathrm{Ca}(\mathrm{II})(\mathrm{B})$ and $\mathrm{Ca}(\mathrm{I}) / \mathrm{Ca}(\mathrm{II})$ positions $(\mathrm{C})$ at $\mathrm{Ca}^{2+}$ vacancy formation. The most energetically favorable geometry at $\mathrm{Al}^{3+}$ inclusion and $\mathrm{H}^{+}$ release $(\mathrm{C})$. The color-coding is as follows: calcium in $\mathrm{Ca}(\mathrm{I})$ position, green; calcium in $\mathrm{Ca}(\mathrm{II})$ position, blue; phosphorus, pink; oxygen, red; hydrogen, light gray; aluminum, yellow. The $\mathrm{Ca}^{2+}$ vacancy is indicated by the blue dotted line. 


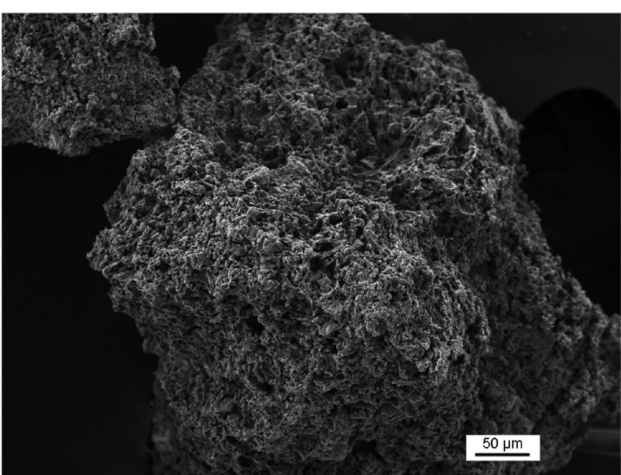

(a)

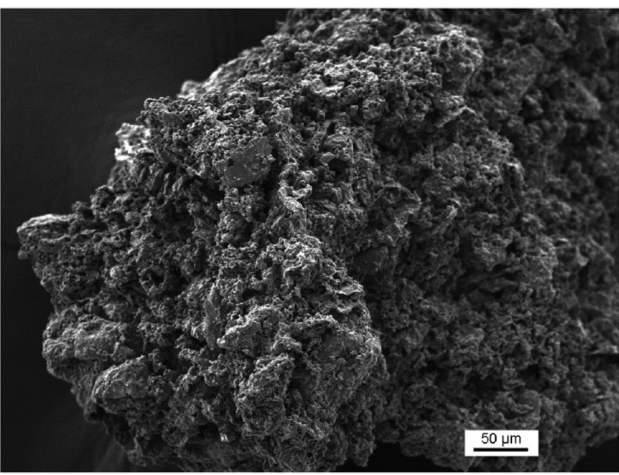

(c)

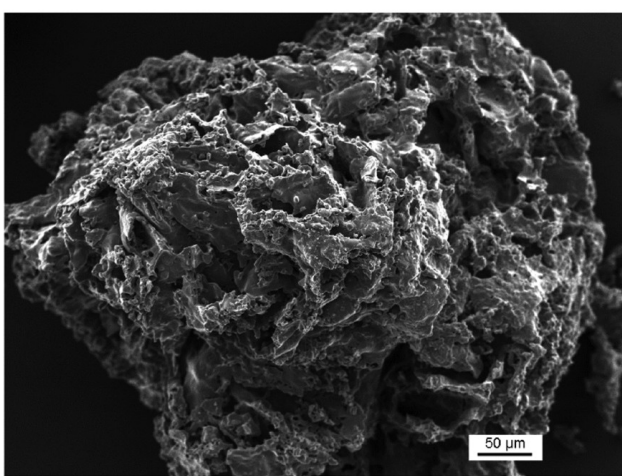

(e)

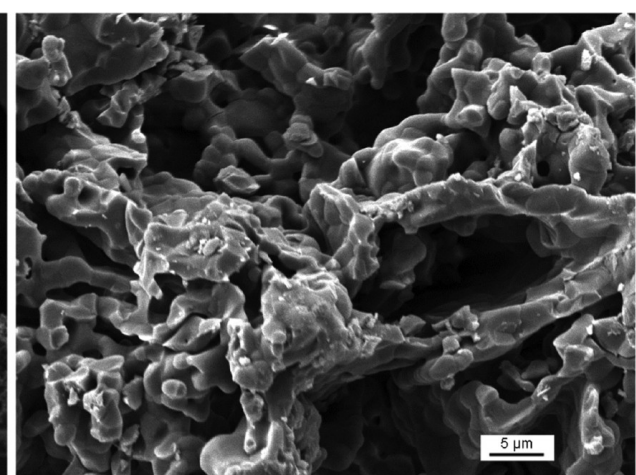

(b)

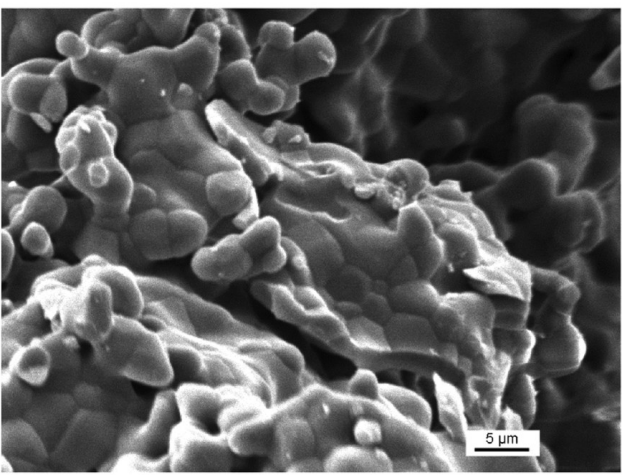

(d)

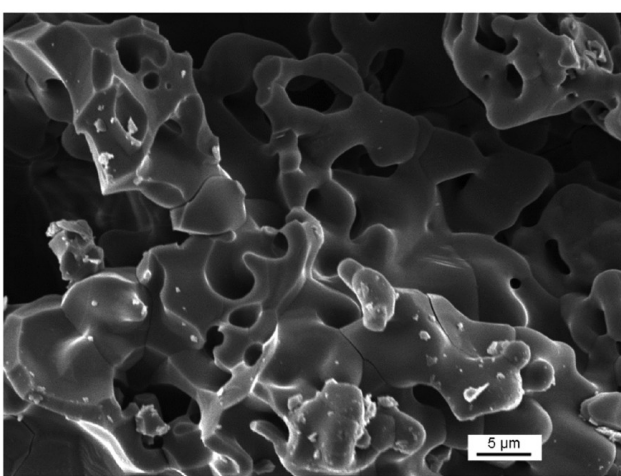

(f)

Figure 14. SEM images of HA-based bioceramic granules (a, b), 0.5Al-HA (c, d), and 20Al-HA (e, f).

Table 6. Optical Density of Formazan Solution (OD; au, MTT Test) and Pool of Viable Cells (PVC, \% Compared to Control) in the Dynamics of Cultivation of Human Osteosarcoma MG-63 on the Bioceramic Granules and Set Cements and Polystyrene (Control)

\begin{tabular}{|c|c|c|c|c|c|}
\hline \multirow[b]{2}{*}{ samples } & & \multicolumn{3}{|c|}{ day of incubation } & \multirow[b]{2}{*}{ increase of cell population, 7 vs 1 day, $\%$} \\
\hline & & 1 & 3 & 7 & \\
\hline \multirow[t]{2}{*}{ control (polystyrene) } & OD & $0.498 \pm 0.004$ & $0.887 \pm 0.007$ & $1.090 \pm 0.011$ & 118.8 \\
\hline & PVC & $100 \%$ & $100 \%$ & $100 \%$ & \\
\hline \multirow[t]{2}{*}{ HA } & OD & $0.571 \pm 0.027^{a}$ & $1.082 \pm 0.012^{a}$ & $1.088 \pm 0.001$ & 90.5 \\
\hline & PVC & $114.6 \%$ & $122.0 \%$ & $99.8 \%$ & \\
\hline \multirow[t]{2}{*}{ 0.5Al-HA } & OD & $0.580 \pm 0.009^{a}$ & $1.124 \pm 0.024^{a}$ & $1.265 \pm 0.033^{a}$ & 118.1 \\
\hline & PVC & $116.5 \%$ & $126.7 \%$ & $116.1 \%$ & \\
\hline \multirow[t]{2}{*}{ 20Al-HA } & OD & $0.682 \pm 0.013^{a}$ & $1.348 \pm 0.016^{a}$ & $1.437 \pm 0.015^{a}$ & 110.7 \\
\hline & PVC & $136.9 \%$ & $152.0 \%$ & $131.8 \%$ & \\
\hline
\end{tabular}

$a_{p}<0.05$ in comparison with the control (Student's $t$-test). 
clearly indicate that less energy is needed to introduce $\mathrm{Mn}^{2+}$ simultaneously with the nitrate ions than to insert the separate impurities. $^{46}$

Thus, the $\mathrm{Al}^{3+}$ incorporation slightly changes the lattice parameters and leads to the local rearrangement of ions in its proximity; the most pronounced distortion occurs in the anion channel. On nitrate codoping, $\mathrm{Al}^{3+}$ tends to keep the HA-like local surrounding and, therefore, tends to exclude the nitrate impurity from the coordination sphere.

3.4. In Vitro Investigations. SEM images of the obtained bioceramic granules are presented in Figure 14. Bioceramic granules are characterized by the size of $0.5-1 \mathrm{~mm}$, while the grain size is up to $5 \mu \mathrm{m}$. The grains formed the porous skeleton with the bimodal porous distribution of $10-50 \mu \mathrm{m}$ porous channels and $0.1-0.5 \mu \mathrm{m}$ small pores. All samples did not cause cytotoxicity in relation to the osteosarcoma cells. The PVC of all bioceramic samples is higher than $100 \%$ and increases with $\mathrm{Al}$ growth (Table 6).

According to the MTT test, the obtained granule surfaces supported the adherence and proliferative activity of human MG-63 osteosarcoma cells (Figure 15). The cultivation of the

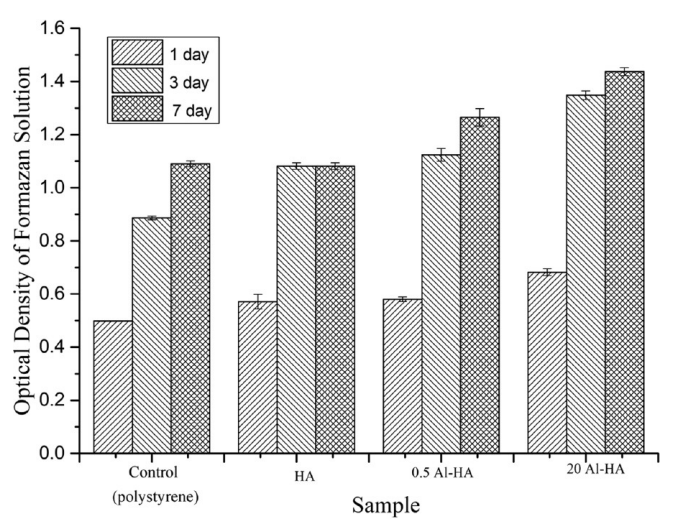

Figure 15. Optical density of formazan solution in the dynamics of cultivation of MG-63 on the bioceramic granules and polystyrene, MTT test ( $p<0.05$ in comparison with the control).

cells on the HA and 0.5Al-HA materials did not demonstrate a significant difference in the optical density of the formazan solution compared with the control-the polystyrene media; at the same time, 20Al-HA possessed more strongly marked matrix characteristics.

The results show that $\mathrm{HA}$ and $\mathrm{Al}-\mathrm{HA}$ materials have cytocompatibility, that is, nontoxicity and marked matrix characteristics of the surface.

\section{CONCLUSIONS}

In the present work, the Al-enriched HAs with a substitution degree up to $20 \mathrm{~mol} \%$ were synthesized by the coprecipitation route and investigated by various analytical tools. The introduction of $\mathrm{Al}$ resulted in a decrease of crystallinity degree and formation of highly anisotropic particles. The influence of $\mathrm{Al}$ on the carbonate and nitric radicals was established by EPR and ENDOR. DFT calculations confirm pronounced distortion in the anion channel. We demonstrated the possibility of introduction of a high amount of $\mathrm{Al}$ due to the substitution of $\mathrm{Ca}$ accompanied by the release of protons from HA structure. The scheme of the proposed charge compensation with the trivalent cation introduction was demonstrated for the first time.
Enhanced proliferation activity of MG-63 cells due to high $\mathrm{Al}$ introduction in the HA structure is shown.

\section{AUTHOR INFORMATION}

\section{Corresponding Authors}

*E-mail: margo.goldberg@yandex.ru. Tel.: +7-929-651-63-31 (M.G.).

*E-mail: marat.gafurov@kpfu.ru, Tel.: +7-843-292-64-80 (M.G.).

ORCID ${ }^{\circ}$

Marat Gafurov: 0000-0002-2179-2823

Vladimir Komlev: 0000-0003-2068-7746

Notes

The authors declare no competing financial interest.

\section{ACKNOWLEDGMENTS}

The powder synthesis; XRD, FTIR, SEM, and TEM characterizations; and the MTT test were conducted with part financial support of Russian Foundation for Basic Research (Grant no. 18-33-20170). EPR and ENDOR measurements were financially supported by Russian Foundation for Basic Research (Grant no. 18-29-11086). The DFT calculations were carried out using the equipment of the shared research facilities of HPC computing resources at Lomonosov Moscow State University and the Joint Supercomputer Center of the Russian Academy of Sciences. The DFT calculations were partly financially supported by Russian Foundation for Basic Research (Grant no. 18-44-160026).

\section{REFERENCES}

(1) Barinov, S. M. Calcium phosphate-based ceramic and composite materials for medicine. Russ. Chem. Rev. 2010, 79, 13-29.

(2) Laskus, A.; Kolmas, J. Ionic substitutions in non-apatitic calcium phosphates. Int. J. Mol. Sci. 2017, 18, 2542.

(3) Tite, T.; Popa, A. C.; Balescu, L.; Bogdan, I.; Pasuk, I.; Ferreira, J.; Stan, G. Cationic substitutions in hydroxyapatite: current status of the derived biofunctional effects and their in vitro interrogation methods. Materials 2018, 11, 2081.

(4) Kaygili, O.; Tatar, C.; Yakuphanoglu, F.; Keser, S. Nano-crystalline aluminum-containing hydroxyapatite based bioceramics: synthesis and characterization. J. Sol-Gel Sci. Technol. 2013, 65, 105-111.

(5) Kalkandelen, C.; Suleymanoglu, M.; Kuruca, S. E.; Akan, A.; Oktar, F. N.; Gunduz, O. Part 2: biocompatibility evaluation of hydroxyapatite-based clinoptilolite and $\mathrm{Al}_{2} \mathrm{O}_{3}$ composites. J. Aust. Ceram. Soc. 2017, 53, 217-223.

(6) Kolekar, T. V.; Thorat, N. D.; Yadav, H. M.; Magalad, V. T.; Shinde, M. A.; Bandgar, S. S.; Kim, J. H.; Agawane, G. L. Nanocrystalline hydroxyapatite doped with aluminium: a potential carrier for biomedical applications. Ceram. Int. 2016, 42, 5304-5311.

(7) Perl, D. P. Relationship of aluminum to Alzheimer's disease. Environ. Health Perspect. 1985, 63, 149-153.

(8) Rondeau, V.; Jacqmin-Gadda, H.; Commenges, D.; Helmer, C.; Dartigues, J. F. Aluminum and silica in drinking water and the risk of Alzheimer's disease or cognitive decline: findings from 15-year followup of the PAQUID cohort. Am. J. Epidemiol. 2008, 169, 489-496.

(9) Alexander, J.; Gronnesby, J. K.; Bakketeig, L. S.; Edwardson, J. A.; et al. Content of brain aluminum is not elevated in Alzheimer disease. Alzheimer Dis. Assoc. Disord. 1996, 10, 171-174.

(10) Wang, M.; Wang, L.; Shi, C.; Sun, T.; Zeng, Y.; Zhu, Y. The crystal structure and chemical state of aluminum-doped hydroxyapatite by experimental and first principles calculation studies. Phys. Chem. Chem. Phys. 2016, 18, 21789-21796.

(11) Gupta, A.; Manohar, C. S.; Siva Kumar, B. Optimization of cation-doped nano-hydroxyapatite in combination with amorphous 
aluminum hydroxide for defluoridation. Water Supply 2019, 19, 16861694.

(12) Nie, Y.; Hu, C.; Kong, C. Enhanced fluoride adsorption using $\mathrm{Al}$ (III) modified calcium hydroxyapatite. J. Hazard. Mater. 2012, 233234, 194-199.

(13) Rahmanian, A.; Ghaziaskar, H. S. Continuous dehydration of ethanol to diethyl ether over aluminum phosphate-hydroxyapatite catalyst under sub and supercritical condition. J. Supercrit. Fluids 2013, $78,34-41$.

(14) Takahashi, H.; Yashima, M.; Kakihana, M.; Yoshimura, A. A differential scanning calorimeter study of the monoclinic $(\mathrm{P} 21 / \mathrm{b}) \leftrightarrow$ hexagonal $(\mathrm{P} 63 / \mathrm{m})$ reversible phase transition in hydroxyapatite. Thermochim. Acta 2001, 371, 53-56.

(15) Elliott, J. C.; Mackie, P. E.; Young, R. A. Monoclinic hydroxyapatite. Science 1973, 180, 1055-1057.

(16) Kay, M. I.; Young, R. A.; Posner, A. S. Crystal structure of hydroxyapatite. Nature 1964, 204, 1050-1052.

(17) Shannon, R. D. Revised effective ionic radii and systematic studies of interatomic distances in halides and chalcogenides. Acta Crystallogr., Sect. A: Cryst. Phys., Diffr., Theor. Gen. Crystallogr. 1976, 32, 751-767.

(18) Nounah, A.; Lacout, J. L.; et al. Localization of cadmium in cadmium-containing hydroxy-and fluorapatites. J. Alloys Compd. 1992, $188,141-146$.

(19) Wakamura, M.; Kandori, K.; Ishikawa, T. Surface structure and composition of calcium hydroxyapatites substituted with $\mathrm{Al}(\mathrm{III})$, $\mathrm{La}$ (III) and Fe(III) ions. Colloids Surf., A 2000, 164, 297-305.

(20) Fahami, A.; Nasiri-Tabrizi, B.; Beall, G. W.; Basirun, W. J. Structural insights of mechanically induced aluminum-doped hydroxyapatite nanoparticles by Rietveld refinement. Chin. J. Chem. Eng. 2017, $25,238-247$.

(21) Goldberg, M. A.; Smirnov, V. V.; Protsenko, P. V.; Antonova, O. S.; Smirnov, S. V.; Fomina, A. A.; Konovalov, A. A.; Leonov, A. V.; Ashmarin, A. A.; et al. Influence of aluminum substitutions on phase composition and morphology of $\beta$-tricalcium phosphate nanopowders. Ceram. Int. 2017, 43, 13881-13884.

(22) Gol'dberg, M. A.; Smirnov, V. V.; Ievlev, V. M.; Barinov, S. M.; Kutsev, S. V.; Shibaeva, T. V.; Shvorneva, L. I. Influence of ripening time on the properties of hydroxyapatite-calcium carbonate powders. Inorg. Mater. 2012, 48, 181-186.

(23) Guinier, A. X-ray Diffraction in Crystals, Imperfect Crystals, and Amorphous Bodies; Dover Publications: New York, 1994.

(24) Gafurov, M.; Biktagirov, T.; Mamin, G.; Orlinskii, S. A DFT, Xand W-band EPR and ENDOR study of nitrogen-centered species in (nano) hydroxyapatite. Appl. Magn. Reson. 2014, 45, 1189-1203.

(25) Stoll, S.; Schweiger, A. EasySpin, a comprehensive software package for spectral simulation and analysis in EPR. J. Magn. Reson. 2006, 178, 42-55.

(26) Gabbasov, B.; Gafurov, M.; Starshova, A.; Shurtakova, D.; Murzakhanov, F.; Mamin, G.; Orlinskii, S. Conventional, pulsed and high-field electron paramagnetic resonance for studying metal impurities in calcium phosphates of biogenic and synthetic origins. $J$. Magn. Magn. Mater. 2019, 470, 109-117.

(27) Vanderbilt, D. Soft self-consistent pseudopotentials in a generalized eigenvalue formalism. Phys. Rev. B 1990, 41, 7892.

(28) Giannozzi, P.; Baroni, S.; Bonini, N.; Calandra, M.; Car, R.; Cavazzoni, C.; Gironcoli, S.; Fabris, S.; Fratesi, G.; Gebauer, R.; et al. QUANTUM ESPRESSO: a modular and open-source software project for quantum simulations of materials. J. Phys.: Condens. Matter 2009, 21, No. 395502.

(29) Perdew, J. P.; Burke, K.; Ernzerhof, M. Generalized gradient approximation made simple. Phys. Rev. Lett. 1996, 77, 3865.

(30) Yashima, M.; Yonehara, Y.; Fujimori, H. Experimental visualization of chemical bonding and structural disorder in hydroxyapatite through charge and nuclear-density analysis. J. Phys. Chem. C 2011, 115, 25077-25087.

(31) Biktagirov, T.; Gafurov, M.; Mamin, G.; Klimashina, E.; Putlayev, V.; Orlinskii, S. Combination of EPR measurements and DFT calculations to study nitrate impurities in the carbonated nanohydroxyapatite. J. Phys. Chem. A 2014, 118, 1519-1526.

(32) Biktagirov, T.; Gafurov, M.; Iskhakova, K.; Mamin, G.; Orlinskii, S. Phonon spectrum in hydroxyapatite: calculations and EPR study at low temperatures. J. Low Temp. Phys. 2016, 185, 627-632.

(33) Monkhorst, H. J.; Pack, J. D. Special points for Brillouin-zone integrations. Phys. Rev. B 1976, 13, 5188.

(34) Komlev, V. S.; Barinov, S. M.; Koplik, E. V. A method to fabricate porous spherical hydroxyapatite granules intended for time-controlled drug release. Biomaterials 2002, 23, 3449-3454.

(35) Mosmann, T. Rapid colorimetric assay for cellular growth and survival: application to proliferation and cytotoxicity assays. J. Immunol. Methods 1983, 65, 55-63.

(36) França, R.; Samani, T. D.; Bayade, G.; Yahia, L. H.; Sacher, E. Nanoscale surface characterization of biphasic calcium phosphate, with comparisons to calcium hydroxyapatite and $\beta$-tricalcium phosphate bioceramics. J. Colloid Interface Sci. 2014, 420, 182-188.

(37) Oktar, F. N.; Kesenci, K.; Piskin, E. Characterization of processed tooth hydroxyapatite for potential biomedical implant applications. Artif. Cells, Blood Substitutes, Biotechnol. 1999, 27, 367-379.

(38) Rau, J. V.; Wu, V. M.; Graziani, V.; Fadeeva, I. V.; Fomin, A. S.; Fosca, M.; Uskokovic, V. The bone building blues: Self-hardening copper-doped calcium phosphate cement and its in vitro assessment against mammalian cells and bacteria. Mater. Sci. Eng., C 2017, 79, 270279.

(39) Gafurov, M.; Biktagirov, T.; Yavkin, B.; Mamin, G.; Filippov, Y.; Klimashina, E.; Putlayev, E. V.; Orlinskii, S. Nitrogen-containing species in the structure of the synthesized nano-hydroxyapatite. JETP Lett. 2014, 99, 196-203.

(40) Merry, J. C.; Gibson, I. R.; Best, S. M.; Bonfield, W. Synthesis and characterization of carbonate hydroxyapatite. J. Mater. Sci.: Mater. Med. 1998, 9, 779-783.

(41) Moens, P. D. W.; Callens, F. J.; Matthys, P. F. A.; Boesman, E. R.; Verbeeck, R. M. H. An EPR study of carbonate and ozonide radicals in carbonated apatites synthesized from aqueous solutions. Appl. Magn. Reson. 1994, 6, 121-144.

(42) Fattibene, P.; Callens, F. EPR dosimetry with tooth enamel: a review. Appl. Radiat. Isot. 2010, 68, 2033-2116.

(43) Ishchenko, S.; Vorona, I.; Okulov, S. ENDOR study of irradiated tooth enamel. Semicond. Phys., Quantum Electron. Optoelectron. 1999, 2, 84-92.

(44) Fisher, D. J.; McConnell, D. Aluminum-rich apatite. Science 1969, 164, 551-553.

(45) Vorona, I. P.; Nosenko, V. V.; Baran, N. P.; Ishchenko, S. S.; Lemishko, S. V.; Zatovsky, I. V.; Strutynska, N. Y. EPR study of radiation-induced defects in carbonate-containing hydroxyapatite annealed at high temperature. Radiat. Meas. 2016, 87, 49-55.

(46) Gafurov, M.; Biktagirov, T.; Mamin, G.; Klimashina, E.; Putlayev, V.; Kuznetsova, L.; Orlinskii, S. The Interplay of manganese and nitrate in hydroxyapatite nanoparticles as revealed by pulsed EPR and DFT. Phys. Chem. Chem. Phys. 2015, 17, 20331-20337.

(47) Gafurov, M. R.; Biktagirov, T. B.; Mamin, G. V.; Shurtakova, D. V.; Klimashina, E. S.; Putlyaev, V. I.; Orlinskii, S. B. Study of the effects of hydroxyapatite nanocrystal codoping by pulsed electron paramagnetic resonance methods. Phys. Solid. State 2016, 58, 469-474.

(48) Shurtakova, D.; Yavkin, B.; Gafurov, M.; Mamin, G.; Orlinskii, S.; Kuznetsova, L.; Bakhteev, S.; Ignatyev, I.; Smirnov, I.; Fedotov, A.; Komlev, V. Study of radiation-induced stable radicals in synthetic octacalcium phosphate by pulsed EPR. Magn. Reson. Solids 2019, 21, 19105. 